\title{
Enzyme-catalyzed C-F bond formation and cleavage
}

\author{
Wei Tong ${ }^{1,2} \mathbb{C}$, Qun Huang ${ }^{1,2}$, Min $\mathrm{Li}^{1,2}$ and Jian-bo Wang ${ }^{1,2^{*}}$
}

\begin{abstract}
Organofluorines are widely used in a variety of applications, ranging from pharmaceuticals to pesticides and advanced materials. The widespread use of organofluorines also leads to its accumulation in the environment, and two major questions arise: how to synthesize and how to degrade this type of compound effectively? In contrast to a considerable number of easy-access chemical methods, milder and more effective enzymatic methods remain to be developed. In this review, we present recent progress on enzyme-catalyzed C-F bond formation and cleavage, focused on describing C-F bond formation enabled by fluorinase and C-F bond cleavage catalyzed by oxidase, reductase, deaminase, and dehalogenase.
\end{abstract}

Keywords: Organofluorines, C-F bonds, Enzyme-catalyzed, Degradation, Formation

\section{Introduction}

Incorporation of fluorine into organic compounds usually endows organofluorines with unique chemical and physical properties, a strategy that has been successfully applied in agrochemicals, materials science, and pharmaceutical chemistry (Phelps 2004; Müller et al. 2007; Shah and Westwell 2007; Hagmann 2008; Nenajdenko et al. 2015; Zhang et al. 2016; Lowe et al. 2017). Especially in medicinal chemistry, the unique elemental properties of fluorine have been proved to enhance metabolic stability and alter pharmacokinetic characteristics without increasing the apparent spatial volume; thus, more than $20 \%$ of drugs are organofluorines (Zhou et al. 2016; Gillis et al. 2015; Spooner et al. 2019). The wide application of organofluorines has motivated fast methodology development for fluorine incorporation (Purser et al. 2008; Berger et al. 2011). In contrast to their synthesis, their degradation has also attracted significant attention due to their increased use and the cumulative pollution resulting from their high stabilities.

Chemists have developed versatile methods for the formation and cleavage of $\mathrm{C}-\mathrm{F}$ bonds, but these methods

\footnotetext{
*Correspondence: jwang@hunnu.edu.cn

${ }^{1}$ Key Laboratory of Phytochemistry R\&D of Hunan Province, College of Chemistry and Chemical Engineering, Hunan Normal University, Changsha 410081, People's Republic of China

Full list of author information is available at the end of the article
}

usually require harsh conditions and are not environment friendly (Dillert et al. 2007; Lin et al. 2012; Sulbaek Andersen et al. 2005). To solve these problems, development of mild and green methods is urgently needed. Biocatalysis has been playing an increasingly more important role in modern chemistry due to its high efficiency, specific selectivity, and more environmentally friendly characteristics compared to chemical catalysis. Thus, introducing biocatalytic methods into organic fluorine chemistry is a good choice to counter the deficiencies of chemical catalysis (Kim et al. 2000; Liu and Avendaño 2013; Murphy 2016; Rotander et al. 2012). Although biocatalysis has achieved significant progress in recent years, the field of biocatalytic $\mathrm{C}-\mathrm{F}$ bond formation and cleavage is almost at an open stage.

Since fluorine atoms are very small and strongly electro-negative, when in an aqueous system fluoride ions are always tightly wrapped by the water molecules, and thus, it is very difficult to form $\mathrm{C}-\mathrm{F}$ bonds in an aqueous system (O'Hagan 2008; Ni and $\mathrm{Hu} 2016$ ). Therefore, fluorine-containing natural products are very rare despite the fact that elemental fluorine is the most fecund halogen in the Earth's crust (O'Hagan and Deng 2014). To the best of our knowledge, only two different examples of enzymecatalyzed $\mathrm{C}-\mathrm{F}$ bond formation have been reported: one is catalyzed by a mutant of glycosyltransferase, which catalyzes $\alpha$-fluoroglycosides as transient intermediates 
from DNP-activated sugars (Zechel et al. 2001), and the other is the natural fluorinase, prompting the conversion of $5^{\prime}$-fluoro-5'-deoxyribose-1-phosphate (5'-FRP) from $S$-adenosyl-L-methionine (SAM) (Deng et al. 2004). In this review, we focus on summarizing the recent progress in mining and directed evolution of fluorinase and expect to inspire the development of more unnatural fluorinases in the future.

The $\mathrm{C}-\mathrm{F}$ bond is the strongest $\sigma$ bond, and thus, it is difficult to cleave it under mild conditions (Goldman 1969; Lemal 2004). When hydrogen is substituted by fluorine, the metabolic stability of the compounds will be significantly improved; this property benefits the pharmaceutical industry, but leads to the accumulation of organofluorines in the environment (Wang et al. 2016). Enzyme-catalyzed $\mathrm{C}-\mathrm{F}$ bond cleavage has attracted attention from researchers in environmental protection, $\mathrm{C}-\mathrm{F}$ bond activation, and enzymology, and several reviews have been published on the subject (Natarajan et al. 2005). However, in recent years, reports in this area have been very rare. Herein, therefore, we present recently published examples of enzyme-catalyzed $\mathrm{C}-\mathrm{F}$ bond cleavage, dividing them into two types: hydrolytic defluorination, and oxireductive defluorination. Hopefully, this review will attract increasing numbers of workers to this important field.

\section{Enzyme-catalyzed C-F bond formation}

The first natural organofluorine compound, identified in 1943, was fluoroacetate, a metabolite of the Southern African plant Dichapetalum cymosum (Marais 1943, 1944). The second one was isolated in 1956 from Streptomyces calvus; it is a nucleoside product named nucleocidin 1 which belongs to a new form of fluorine metabolites (Scheme 1a). Subsequently, the third structurally novel, fluorine-containing natural product 4-fluorothreonine was isolated from the bacterium Streptomyces cattleya in 1986 (Sanada et al. 1986). Despite considerable interest and a variety of speculative suggestions for uncovering the biochemical mechanism of fluorination, no specific details of fluorination's biochemistry in any organism were provided until 2002. This milestone regarding fluorinase was published in 2002 by O'Hagan's group (O'Hagan et al. 2002), who first described an enzymatic reaction occurring in the bacterium Streptomyces cattleya that catalyzes the conversion of fluoride ions and S-adenosylmethionine (SAM) to $5^{\prime}$-fluoro-5'deoxyfluoroadeno-sine (5'-FDA) (O'Hagan et al. 2002; see Scheme 1b). In the following year, O'Hagan's team isolated and characterized fluorinase from Streptomyces cattleya (Schaffrath et al. 2003), and the crystal structure of fluorinase was resolved by the same group in 2004 (Dong et al. 2004; Deng et al. 2004). Although the basic enzyme was characterized before 2005, it took approximately 10 years to clarify the biosynthetic pathway of all fluorinated products in Streptomyces cattleya, and their work proved that fluorinating enzyme that converts inorganic fluorine into organic fluorine (Deng et al. 2006; Zhu et al. 2007; Winkler et al. 2008; Dall'Angelo et al. 2013; O'Hagan and Deng 2014; Wang et al. 2014; Carvalho and Oliveira 2017). However, attempts to identify enzymes that biosynthesize nucleocidin $\mathbf{1}$ have failed for decades, because the production of this molecule has been mysteriously silenced in the bacterium Streptomyces calvus (Jenkins et al. 1976; Nashiru et al. 2001; Zechel et al. 2003). In 2015, Zechel's group reported that complementation of S. calvus ATCC13382 with a functional bldAencoded Leu-tRNA ${ }^{\text {UUA }}$ molecule restores the production of nucleocidin $\mathbf{1}$ and identified the genes encoding the biosynthesis of the $5^{\prime}$-O-sulfamate group of the nucleocidin 1 (Zhu et al. 2015). In the next year, O'Hagan's group provided the first biosynthetic data on nucleocidin 1 assembly from isotope labeling studies (Bartholomé et al. 2016; Feng et al. 2017). However, there was still no illumination for the mechanism of fluorination involved in this biosynthetic pathway. In 2019, O'Hagan group disclosed two structures of novel fuorometabolites in S. calvus, which belong to 3'-O-glucosylated, 4'-fuoro-riboadenosines (6 and 7) (Scheme 1a). They are analogous of nucleocidin 1 and suspect to incorporate fluorine via a same biocatalytic pathway (Feng et al. 2019). The identification of these metabolites highly suggests that there is a new type of fluorinase existing in S. calvus which deserves our attention.

Although the specific activity of fluorinase has attracted considerable attention, its application is limited due to the drawbacks of narrow substrate scope and low activity. To explore its utilization, it is necessary to mine new types of fluorinase or improve the activity of known forms of fluorinase by directed evolution. Most research on fluorinase is focused on discovering new forms of fluorinase through gene mining. To date, four new fluorinases have been identified, three of which have been characterized (see Table 1) (Deng et al. 2014; Wang et al. 2014; HimáTong 2014). The first was identified from Streptomyces sp. MA37, a strain isolated in 2011 from Ghana. Full genome sequences of the South American hospital pathogens, Nocardia brasiliensis (Deng et al. 2014; Wang et al. 2014) and Actinoplanes sp. N902-109, were deposited into the public domain in 2012 and 2013, respectively. The draft genome of the marine bacterium Streptomyces xinghaiensis NRRL B-24674 was deposited in the public domain in 2011. More recently, a new fluorinase (FIA) gene has been identified in the Streptomyces xinghaiensis genome. Full genome sequencing of the organism revealed a gene encoding of a putative 

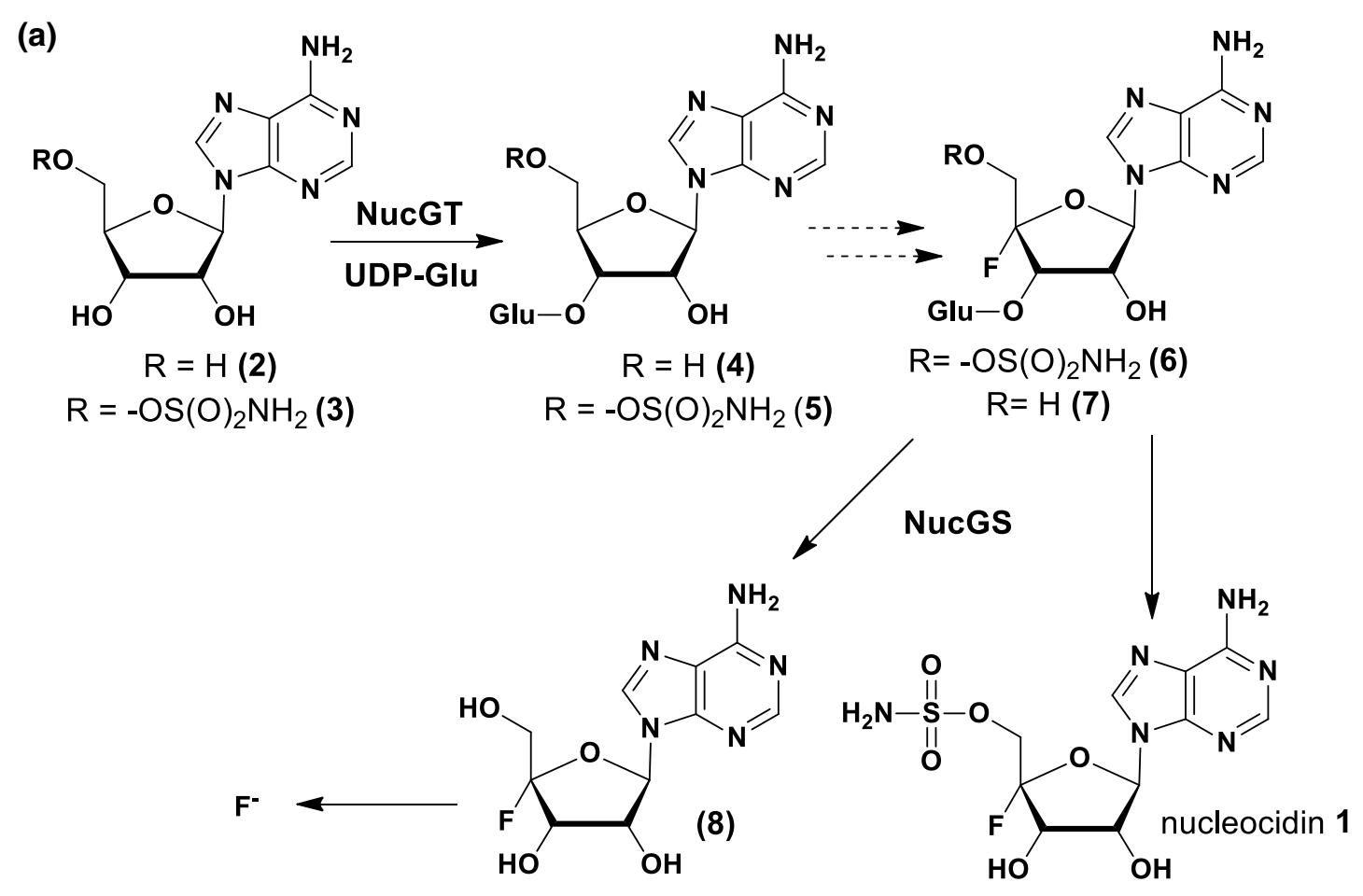

(b) $\mathrm{O}^{-}$

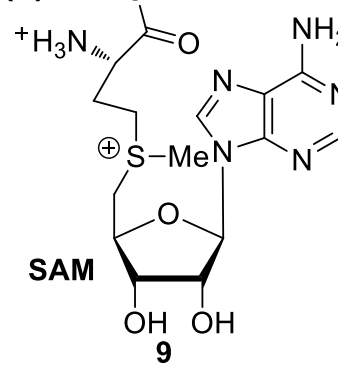

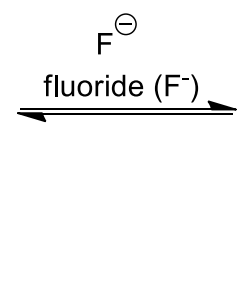<smiles>Nc1ccnc2c1ncn2C1OC2OC1C(O)C2O</smiles>

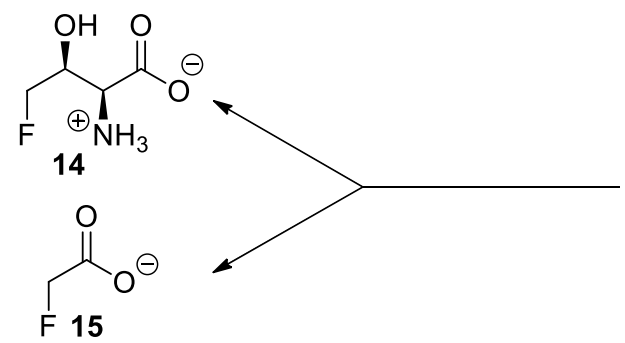<smiles>O=CCF</smiles><smiles>O=P([O-])([O-])OC1OC(O)(CF)C(O)C1O</smiles>

12

Scheme 1 a Putative minimal pathway for nucleocidin 1 biosynthesis. $\mathbf{b}$ Intermediates and enzymes on the biosynthesis of fluoroacetate and 4-fluorothreonine

fluorinase with $80 \%$ sequence identity to that of Streptomyces cattleya. Although the fluorinase in Streptomyces xinghaiensis was not isolated, the production of fluoroacetate in culture suggests a functioning fluorinase. This is the first instance of a fluorometabolite isolated from a marine organism (HimáTong 2014).
In addition to mining new fluorinases, directed evolution has achieved new progress. In 2016, Zhao's group first directed evolution of the fluorinase FIA1 for improved conversion of the non-native substrate $5^{\prime}$-chloro-5'-deoxyade-nosine (5'-CIDA) into $5^{\prime}$-fluoro$5^{\prime}$-deoxyadenosine (5'-FDA) (see Table 2; Sun et al. 
Table 1 Comparative kinetic data of known fluorinase enzymes

\begin{tabular}{lllll}
\hline Fluorinase (FIA) source & SAM $\boldsymbol{K}_{\boldsymbol{m}}(\boldsymbol{\mu M})$ & $\begin{array}{l}\text { Turnover no. } \boldsymbol{k}_{\text {cat }} \\
\left(\mathbf{m i n}^{-\mathbf{1}}\right)\end{array}$ & $\begin{array}{l}\text { Specificity constant } \boldsymbol{k}_{\text {cat }} / \boldsymbol{K}_{\boldsymbol{m}} \\
\left(\mathbf{m M}^{-\mathbf{1}} \mathbf{\mathbf { m i n } ^ { - 1 } )}\right.\end{array}$ & References \\
\hline S. cattleya & $29.2 \pm 2.41$ & 0.083 & 2.84 & Schaffrath et al. 2003 \\
Streptomyce sp. MA37 & $82.4 \pm 18.6$ & 0.262 & 3.18 & Deng et al. 2014 \\
N. brasiliensis & $27.8 \pm 4.23$ & 0.122 & 4.40 & Wang et al. 2014 \\
Actinoplanes sp. N902-109 & $45.8 \pm 7.91$ & 0.204 & 4.44 & Deng et al. 2014 \\
\hline
\end{tabular}

Table 2 Fluorinase variants obtained by directed evolution

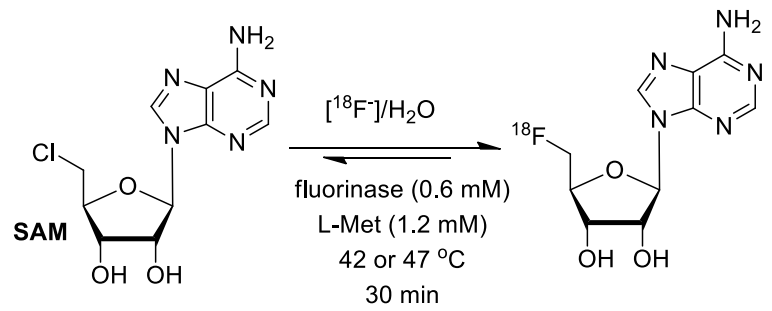

\begin{tabular}{llll}
\hline Fluorinase & $\mathbf{T}\left({ }^{\circ} \mathbf{C}\right)$ & $\begin{array}{l}\mathbf{R C C} \\
\text { (analytical) } \\
\text { (\%) }\end{array}$ & $\mathbf{R C C}^{\mathbf{a}}$ (overall) (\%) \\
\hline FIA1 & 42 & $8 \pm 1$ & $7 \pm 1$ \\
FIA1 & 47 & $11 \pm 2$ & $8 \pm 2$ \\
fah2081 (A279Y) & 42 & $32 \pm 3$ & $24 \pm 2$ \\
fah2114 (F213Y, A279L) & 47 & $46 \pm 2$ & $34 \pm 3$ \\
\hline
\end{tabular}

a Overall $\mathrm{RCC}=\%$ radioactivity in supernatant $\mathrm{W} \% \mathrm{RCC}$ based on radioHPLC. Typical \% radioactivity in supernatant is in the range $73-80 \%$

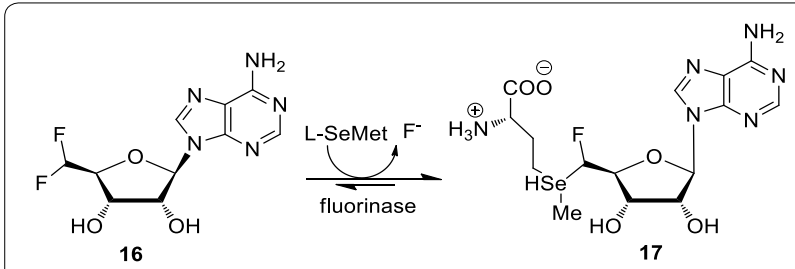

Scheme 2 Enzymatic transformation of $\mathbf{1 6}$ to its corresponding $\mathbf{1 7}$

2016). NNK-based saturated mutagenesis of the active sites (within $5 \AA$ of substrate) was performed on the FIA1 gene to generate libraries for high-throughput screening. The evolutionary variants fah2081 (A279Y) and fah2114 (F213Y and A279L) have been successfully applied to the radiosynthesis of $5^{\prime}-\left[{ }^{18} \mathrm{~F}\right] \mathrm{FDA}$, and their total radiochemical conversion ( $\mathrm{RCC}$ ) is more than threefold higher than wild-type FIA1. In 2016, O'Hagan's group found that fluorinase can be applied to the synthesis of $5^{\prime}, 5^{\prime}$-Difluoro-5'-deoxyadenosine. (see Scheme 2; Thompson et al. 2016). Some research has also been

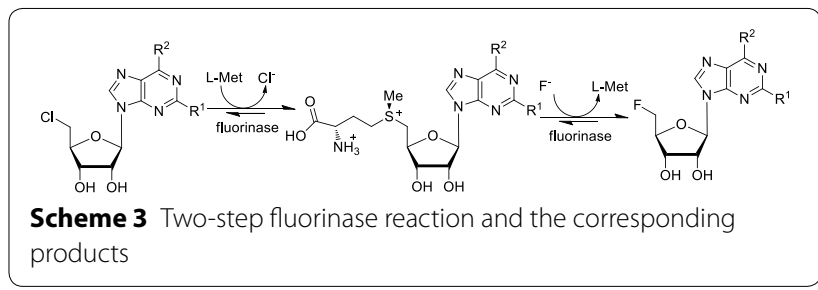

done on the recognition of substrates by fluorinase (Yeo et al. 2017; Sun et al. 2018). In 2017, Yeo's team explored fluorinase specificity (Yeo et al. 2017). In addition, their evolved FIA1 luciferin variants are active against substrates modified at the C-2 and C- 6 positions of the adenine ring, although they are directed against $5^{\prime}$-CIDA 1 and L-Met bottoms and conferred novel activity towards substrates not readily accepted by wild-type FIA1 (see Scheme 3). Regarding the recent research progress on fluorinase, the application of fluorinase is still very limited. We believe that the directed evolution can be used on fluorinase to catalyze more non-natural fluorination reactions.

\section{Enzyme-catalyzed C-F bond cleavage}

Large-scale applications of fluorinated compounds have caused increasing environmental concerns due to their toxicity, global warming potential, environmental persistence, and bioaccumulation character (Douvris and Ozerov 2008; Houde et al. 2006). Environmental biotransformation, one of the most promising strategies with the lowest energy consumption, has provided some encouraging results in cleaving the highly stable $\mathrm{C}-\mathrm{F}$ bond, the dissociation energy of which is the highest among all the natural products. At present, there are two ways of catalyzing the cleavage of $\mathrm{C}-\mathrm{F}$ bonds by enzymes: hydrolytic defluorination and oxireductive defluorination.

The presence of naturally produced fluoroacetate in the environment has resulted in the evolution of mechanisms to degrade this substrate. Goldman identified the first microbial defluorinases in Pseudomonas sp., which catalyzed the hydrolytic cleavage of the $\mathrm{C}-\mathrm{F}$ bond, yielding glycolate and fluoride ions (Goldman 
1965). Subsequently, other defluorinases were isolated from several micro-organisms (Goldman 1965; Kawasaki et al. 1981; Walker and Lien 1981; Liu et al. 1998; Kurihara et al. 2003; Donnelly and Murphy 2009). The mechanism of $\mathrm{C}-\mathrm{F}$ bond cleavage by defluorinases has been investigated (see Fig. 1; Liu et al. 1998; Chan et al. 2011; Kim et al. 2017; Mehrabi et al. 2019), and a twostep reaction mechanism for fluoroacetic acid dehalogenase was proposed. First, aspartate attacks $\alpha$-carbon connected with $\mathrm{F}$ atom. This leads to the leaving of $\mathrm{F}$ atom from the substrate. The covalent intermediate, thus, produced is then hydrolyzed by a histidine-activated water molecule, which is assisted by the second aspartate residue. The catalytic process involves the conservative aspartic acid-histidine-aspartic acid catalytic triad. In 2017, Reetz's group reported a study of substrate range and enantioselectivity of defluorinases via using stereochemical probes (Wang et al. 2017). A favorable (S)configuration was observed in the fast reaction using racemic 2-fluoro-2-phenylacetic acid (see Scheme 4a). Surprisingly, the results show that the enzyme pocket can accept a larger substrate than the natural substrate fluoroacetic acid, and that this non-natural compound is more reactive than fluoroacetic acid. Another hydrolyzed defluorinated enzyme is transaminases (Cuetos et al. 2016); transaminases are valuable enzymes in industrial biocatalysis and enable the preparation of optically pure amines. Lavandera reported a non-natural reaction type of transaminase, and the promiscuous reactivity of transaminases can be applied to obtain a series of enantiopure $\beta$-fluoroamines by an unprecedented formal tandem hydrodefluorination or deamination kinetic resolution of racemic $\beta$-fluoroamines (see Scheme $4 b$ ).

Oxireductive dehalogenation is a common pathway for detoxification of organic halide by micro-organisms. Biocatalytic oxidation and reduction defluorination by micro-organisms containing organic fluorine compounds have been reviewed to analyze their ability to handle such specific chemicals and to explore the potential of this knowledge in biotechnology applications (Natarajan et al. 2005). To avoid unnecessary repetition, here we only introduce works published in the last 5 years. In 2016, Bergen's team reported that ATPdependent $\mathrm{BzCoA}$ reductase can promote $\mathrm{C}-\mathrm{F}$ bond cleavage. An ATP-dependent study of defluorination

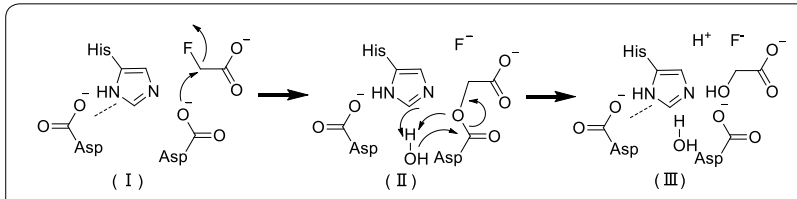

Fig. 1 Proposed two-step reaction mechanism of fluoroacetate

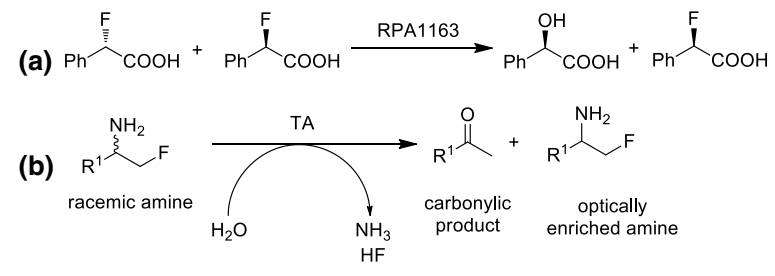

Scheme 4 Enzymatic hydrolysis of defluorination reaction: a hydrolytic kinetic resolution of racemate catalyzed by fluoroacetate dehalogenase RPA1163 and b novel tandem hydrodefluorination/ deamination kinetic resolution of racemic $\beta$-fluoroamines

of 4-fluorobenzoacyl-CoA (4-F-BzCoA) with benzoyl$\mathrm{CoA}(\mathrm{BzCoA})$ and $\mathrm{HF}$ catalyzed by class I BzCoA reductase was carried out. An unprecedented mechanism for reductive arylic $\mathrm{C}-\mathrm{F}$ bond cleavage via a Birch reduction-like mechanism resulting in a formal nucleophilic aromatic substitution was proposed (see Fig. 2; Tiedt et al. 2016). In 2018, Liu et al. reported cleavage of a C-F bond by an engineered cysteine dioxygenase (Whittaker 2003; Simmons et al. 2006; Li et al. 2018). Experimental data suggest that protein-bound $\mathrm{O}_{2}$-dependent carbonhalogen bonds cleave iron centers under mild, physiologically relevant conditions. Although the $\mathrm{C}-\mathrm{F}$ bond is the strongest covalent single bond in organic chemistry, cysteine dioxygenase is able to cleave a $\mathrm{C}-\mathrm{F}$ bond to realize co-factor biogenesis (see Scheme 5a). In 2019, Wang's group discovered that a histidine-linked heme enzyme can catalyze the cleavage of $\mathrm{C}-\mathrm{F}$ by hydroxylation (Wang et al. 2019). LmbB2 has a wide range of catalytic activities toward L-tyrosine analogues, as long as the 4-hydroxyl group is present. The monosubstituted tyrosine analogues represented by 3-fluoro-L-tyrosine presumably bind in two different orientations at the heme

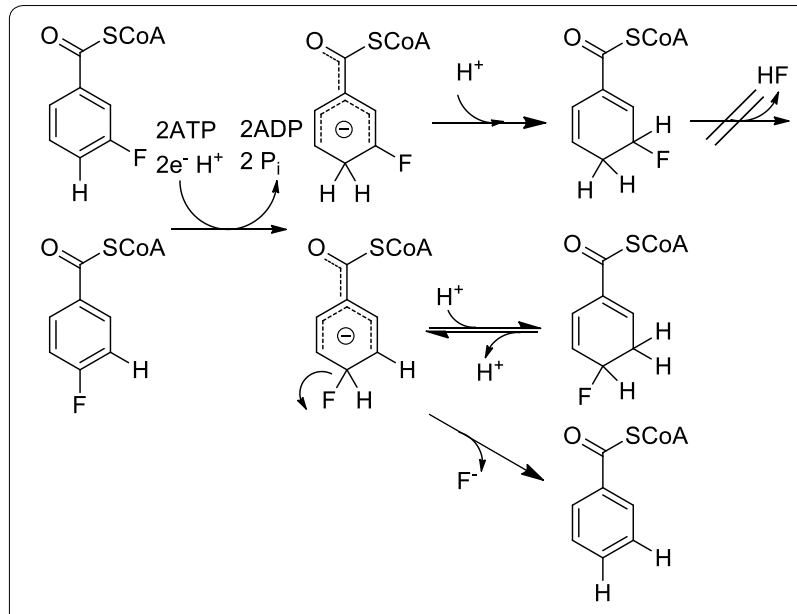

Fig. 2 Possible mechanism for reductive defluorination of $\mathrm{BzCOA}$ by ATP-dependent class I BCR 


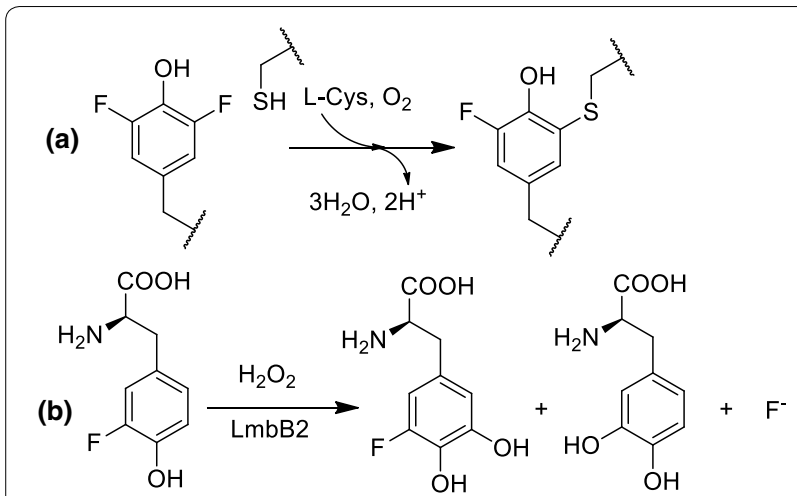

Scheme 5 Enzymatic of defluorination reaction: a cleavage of C-F bond by engineered cysteine dioxygenase and $\mathbf{b}$ summary of $L m b B 2$ reaction for 3-fluoro-L-tyrosine

active site, with the substituents pointing away from or toward the heme center (see Scheme 5b). A mono-substituted tyrosine analog represented by 3 -fluoro-L-tyrosine may have two different binding modes at the heme active site, and the substituent is directed to the center of the heme or away from its center. For example, the $\mathrm{C}-\mathrm{F}$ bond undergoes hydroxylation to generate DOPA. The above describes the enzymatic hydrolysis or oxidation of the $\mathrm{C}-\mathrm{F}$ bond, broadening the scope of fluorine chemistry and further expanding the potential industrial application of natural or engineered proteins.

\section{Conclusions}

Organofluorines play an increasingly important role in the pharmaceutical and agrochemical industries, making the prospect of using enzymatic reactions to form $\mathrm{C}-\mathrm{F}$ bonds bright. However, the extensive use of organofluorines has also caused environmental pollution, and thus, development of a mild green enzyme to degrade these compounds is a matter of urgency. With its highly catalytic selectivity and environmental friendliness, enzymatic catalysis will play an increasingly more important role in fluorine organic chemistry. In this review, details of the formation of $\mathrm{C}-\mathrm{F}$ bonds catalyzed by fluorinase and the cleavage of $\mathrm{C}-\mathrm{F}$ bonds by oxidase, reductase deaminase, and fluoroacetate dehalogenase are demonstrated. These fluorinase and defluorinase all have been isolated and identified for more than a decade, and their catalytic mechanisms illuminated. However, a narrow substrate range or low activity has hindered their application. With the fast development of biotechnology, mining new enzymes or improving their properties by directed evolution holds promise to eliminate these barriers, which will greatly accelerate the development of enzymatic organic fluorine chemistry.

\section{Abbreviations}

5'-FRP: 5'-fluoro-5'-deoxyribose-1-phosphate; SAM: S-adenosyl---methionine; 5'-FDA: 5'-fluoro-5'-deoxyfluoroadeno-sine; FIA: fluorinase; 5'-CIDA: 5'-chloro-5'-deoxyade-nosine; RCC: radiochemical conversion; 4-F-BzCoA: 4-fluorobenzoacyl-CoA; BzCoA: benzoyl-CoA; class I BCR: catalyzed by class I $B z C o A$ reductase; TA: transaminases; LmbB2: tyrosine hydroxylase.

\section{Acknowledgements}

J.-b.W. thanks and the support from Huxiang High-level Talent Gathering Project of Hunan Province (2019RS1040) and the start-up funding from Hunan Normal University.

\section{Authors' contributions}

JW and WT conceived and wrote this paper. QH and ML were involved collecting related material and critical reading of this paper. All authors read and approved the final manuscript.

\section{Availability of data and materials}

All data generated or analyzed during this study are included in this published article.

Ethics approval and consent to participate

Not applicable.

\section{Consent for publication}

Not applicable.

\section{Competing interests}

The authors declare that they have no competing interests.

\section{Author details}

${ }^{1}$ Key Laboratory of Phytochemistry R\&D of Hunan Province, College of Chemistry and Chemical Engineering, Hunan Normal University, Changsha 410081, People's Republic of China. ${ }^{2}$ Key Laboratory of Chemical Biology and Traditional Chinese Medicine Research (Ministry of Education), College of Chemistry and Chemical Engineering, Hunan Normal University, Changsha 410081, People's Republic of China.

Received: 28 September 2019 Accepted: 15 November 2019

Published online: 22 November 2019

\section{References}

Bartholomé A, Janso JE, O'Hagan D (2016) Fluorometabolite biosynthesis: isotopically labelled glycerol incorporations into the antibiotic nucleocidin in Streptomyces calvus. Org Biomol Chem 15(1):61-64

Berger R, Resnati G, Metrangolo P, Weber E, Hulliger J (2011) Organic fluorine compounds: a great opportunity for enhanced materials properties. Chem Soc Rev 40(7):3496-3508

Carvalho MF, Oliveira RS (2017) Natural production of fluorinated compounds and biotechnological prospects of the fluorinase enzyme. Crit Rev Biotechnol 37(7):880-897

Chan PW, Yakunin AF, Edwards EA, Pai EF (2011) Mapping the reaction coordinates of enzymatic defluorination. J Am Chem Soc 133(19):7461-7468

Cuetos A, García-Ramos M, Fischereder EM, Díaz-Rodríguez A, Grogan G, Gotor V, Lavandera I (2016) Catalytic promiscuity of transaminases: preparation of enantioenriched $\beta$-fluoroamines by formal tandem hydrodefluorination/deamination. Angew Chem Int Ed 128(9):3196-3199

Dall'Angelo S, Bandaranayaka N, Windhorst AD, Vugts DJ, van der Born D, Onega M, O'Hagan D (2013) Tumour imaging by positron emission tomography using fluorinase generated $5-\left[{ }^{18} \mathrm{~F}\right]$ fluoro-5-deoxyribose as a novel tracer. Nucl Med Biol 40(4):464-470

Deng H, O'Hagan D, Schaffrath C (2004) Fluorometabolite biosynthesis and the fluorinase from Streptomyces cattleya. Natural product reports 21(6):773-784 
Deng H, Cobb SL, McEwan AR, McGlinchey RP, Naismith JH, O'Hagan D, Spencer JB (2006) The fluorinase from Streptomyces cattleya is also a chlorinase. Angew Chem Int Ed 45(5):759-762

Deng H, Ma L, Bandaranayaka N, Qin Z, Mann G, Kyeremeh K, O'Hagan D (2014) Identification of fluorinases from Streptomyces sp MA37, Norcardia brasiliensis, and Actinoplanes sp N902-109 by genome Mining. ChemBioChem 15(3):364-368

Dillert R, Bahnemann D, Hidaka H (2007) Light-induced degradation of perfluorocarboxylic acids in the presence of titanium dioxide. Chemosphere 67(4):785-792

Dong C, Huang F, Deng H, Schaffrath C, Spencer JB, O'Hagan D, Naismith $J H$ (2004) Crystal structure and mechanism of a bacterial fluorinating enzyme. Nature 427(6974):561

Donnelly C, Murphy CD (2009) Purification and properties of fluoroacetate dehalogenase from Pseudomonas fluorescens DSM 8341. Biotech Lett 31:245-250

Douvris C, Ozerov OV (2008) Hydrodefluorination of perfluoroalkyl groups using silylium-carborane catalysts. Science 321(5893):1188-1190

Feng X, Al Maharik N, Bartholomé A, Janso JE, O'Hagan D (2017) Incorporation of $\left[{ }^{2} \mathrm{H}_{1}\right]-(1 \mathrm{R}, 2 \mathrm{R})$-and $\left[{ }^{2} \mathrm{H}_{1}\right]-(1 \mathrm{~S}, 2 \mathrm{R})$-glycerols into the antibiotic nucleocidin in Streptomyces calvus. Org Biomol Chem 15(38):8006-8008

Feng X, Bello D, Lowe PT, Clark J, O'Hagan D (2019) Two 3'-O- $\beta$-glucosylated nucleoside fluorometabolites related to nucleocidin in Streptomyces calvus. Chemical Science 10(41):9501-9505

Gillis EP, Eastman KJ, Hill MD, Donnelly DJ, Meanwell NA (2015) Applications of fluorine in medicinal chemistry. J Med Chem 58(21):8315-8359

Goldman P (1965) Enzymatic cleavage of carbon-fluorine bond in fluoroacetate. J Biol Chem 240:3434-3438

Goldman P (1969) The carbon-fluorine bond in compounds of biological interest. Science 164(3884):1123-1130

Hagmann WK (2008) The many roles for fluorine in medicinal chemistry. J Med Chem 51(15):4359-4369

HimáTong M (2014) Fluoroacetate biosynthesis from the marine-derived bacterium Streptomyces xinghaiensis NRRL B-24674. Org Biomol Chem 12(27):4828-4831

Houde M, Martin JW, Letcher RJ, Solomon KR, Muir DC (2006) Biological monitoring of polyfluoroalkyl substances: a review. Environ Sci Technol 40(11):3463-3473

Jenkins ID, Verheyden JP, Moffatt JG (1976) 4'-Substituted nucleosides. 2. Synthesis of the nucleoside antibiotic nucleocidin. J Am Chem Soc 98(11):3346-3357

Kawasaki H, Miyoshi K, Tonomura K (1981) Purification, crystallization and properties of haloacetate halidohydro-lase from Pseudomonas species. Agric Biol Chem 45:543-544

Kim BR, Suidan MT, Wallington TJ, Du X (2000) Biodegradability of trifluoroacetic acid. Environ Eng Sci 17(6):337-342

Kim TH, Mehrabi P, Ren Z, Sljoka A, Ing C, Bezginov A, Ye L, Pomès R, Prosser RS, Pai EF (2017) The role of dimer asymmetry and protomer dynamics in enzyme catalysis. Science 355(6322):eaag2355

Kurihara T, Yamauchi T, Ichiyama S (2003) Purification, characterization, and gene cloning of a novel fluoroacetate dehalogenase from Burkholderia sp FA1. J Mol Catal B Enzym 23:347-355

Lemal DM (2004) Perspective on fluorocarbon chemistry. J Organ Chem 69(1):1-11

Li J, Griffith WP, Davis I, Shin I, Wang J, Li F, Liu A (2018) Cleavage of a carbonfluorine bond by an engineered cysteine dioxygenase. Nat Chem Biol 14(9):853

Lin X, Rong F, Fu D, Yuan C (2012) Enhanced photocatalytic activity of fluorine doped $\mathrm{TiO}_{2}$ by loaded with $\mathrm{Ag}$ for degradation of organic pollutants. Powder Technol 219:173-178

Liu J, Avendaño SM (2013) Microbial degradation of polyfluoroalkyl chemicals in the environment: a review. Environ Int 61:98-114

Liu JQ, Kurihara T, Ichiyama S (1998) Reaction mech-anism of fluoroacetate dehalogenase from Moraxella sp. J Biol Chem 273:30897-30902

Lowe PT, Dall'Angelo S, Mulder-Krieger T, IJzerman AP, Zanda M, O'Hagan D (2017) A new class of fluorinated A2A adenosine receptor agonist with application to last-step enzymatic $\left[{ }^{18} \mathrm{~F}\right]$ fluorination for PET imaging. ChemBioChem 18(21):2156-2164

Marais JSC (1943) The isolation of the toxic principle" potassium cymonate" from" Gifblaar" Dichapetalum cymosum (Hook) Engl
Marais JSC (1944) Monofluoroacetic acid, the toxic principle of "gifblaar", Dichapetalum cymosum (Hook) Engl

Mehrabi P, Di Pietrantonio C, Kim TH, Sljoka A, Taverner K, Ing C, Prosser RS (2019) Substrate-based allosteric regulation of a homodimeric enzyme. J Am Chem Soc 141(29):11540-11556

Müller K, Faeh C, Diederich F (2007) Fluorine in pharmaceuticals: looking beyond intuition. Science 317(5846):1881-1886

Murphy CD (2016) Microbial degradation of fluorinated drugs: biochemical pathways, impacts on the environment and potential applications. Appl Microbiol Biotechnol 100(6):2617-2627

Nashiru O, Zechel DL, Stoll D, Mohammadzadeh T, Warren RAJ, Withers SG (2001) $\beta$-Mannosynthase: synthesis of $\beta$-mannosides with a mutant $\beta$-mannosidase. Angew Chem Int Ed 40(2):417-420

Natarajan R, Azerad R, Badet B, Copin E (2005) Microbial cleavage of C-F bond. J Fluorine Chem 126(4):424-435

Nenajdenko VG, Muzalevskiy VM, Shastin AV (2015) Polyfluorinated ethanes as versatile fluorinated $\mathrm{C}_{2}$-building blocks for organic synthesis. Chem Rev 115(2):973-1050

$\mathrm{Ni} \mathrm{C}$, Hu J (2016) The unique fluorine effects in organic reactions: recent facts and insights into fluoroalkylations. Chem Soc Rev 45(20):5441-5454

O'Hagan D (2008) Understanding organofluorine chemistry. An introduction to the C-F bond. Chem Soc Rev 37(2):308-319

O'Hagan D, Deng H (2014) Enzymatic fluorination and biotechnological developments of the fluorinase. Chem Rev 115(2):634-649

O'Hagan D, Schaffrath C, Cobb SL, Hamilton JT, Murphy CD (2002) Biochemistry: biosynthesis of an organofluorine molecule. Nature 416(6878):279

Phelps ME (2004) PET: molecular imaging and its biological applications. Springer Science \& Business Media, Berlin

Purser S, Moore PR, Swallow S, GouverneurV (2008) Fluorine in medicinal chemistry. Chem Soc Rev 37(2):320-330

Rotander A, Kärrman A, van Bavel B, Polder A, Rigét F, Auðunsson GA, Dam M (2012) Increasing levels of long-chain perfluorocarboxylic acids (PFCAs) in Arctic and North Atlantic marine mammals, 1984-2009. Chemosphere 86(3):278-285

Sanada M, Miyano T, Iwadare S, Willlamson JM, Arison BH, Smith JL, Inamine E (1986) Biosynthesis of fluorothreonine and fluoroacetic. J Antibiot 39(2):259-265

Schaffrath C, Deng H, O'Hagan D (2003) Isolation and characterisation of $5^{\prime}$-fluorodeoxyadenosine synthase, a fluorination enzyme from Streptomyces cattleya. FEBS Lett 547(1-3):111-114

Shah P, Westwell AD (2007) The role of fluorine in medicinal chemistry. J Enzyme Inhib Med Chem 22(5):527-540

Simmons CR, Liu Q, Huang Q, Hao Q, Begley TP, Karplus PA, Stipanuk MH (2006) Crystal structure of mammalian cysteine dioxygenase a novel mononuclear iron center for cysteine thiol oxidation. J Biol Chem 281(27):18723-18733

Spooner MJ, Li H, Marques I, Costa PM, Wu X, Howe EN, Félix V (2019) Fluorinated synthetic anion carriers: experimental and computational insights into transmembrane chloride transport. Chem Sci 10(7):1976-1985

Sulbaek Andersen MP, Nielsen OJ, Wallington TJ, Hurley MD, DeMore WB (2005) Atmospheric chemistry of $\mathrm{CF}_{3} \mathrm{OCF}_{2} \mathrm{CF}_{2} \mathrm{H}$ and $\mathrm{CF}_{3} \mathrm{OC}\left(\mathrm{CF}_{3}\right)_{2} \mathrm{H}$ : reaction with $\mathrm{Cl}$ atoms and $\mathrm{OH}$ radicals, degradation mechanism, global warming potentials, and empirical relationship between $\mathrm{k}(\mathrm{OH})$ and $\mathrm{k}(\mathrm{Cl})$ for organic compounds. J Phys Chem A 109(17):3926-3934

Sun H, Yeo WL, Lim YH, Chew X, Smith DJ, Xue B, Ang EL (2016) Directed evolution of a-fluorinase for improved fluorination efficiency with a non-native substrate. Angew Chem Int Ed 128(46):14489-14492

Sun H, Zhao H, Ang EL (2018) A coupled chlorinase-fluorinase system with a high efficiency of trans-halogenation and a shared substrate tolerance. Chem Commun 54(68):9458-9461

Thompson S, McMahon SA, Naismith JH, O'Hagan D (2016) Exploration of a potential difluoromethyl-nucleoside substrate with the fluorinase enzyme. Bioorg Chem 64:37-41

Tiedt O, Mergelsberg M, Boll K, Müller M, Adrian L, Jehmlich N, Boll M (2016) ATP-dependent $\mathrm{C}-\mathrm{F}$ bond cleavage allows the complete degradation of 4-fluoroaromatics without oxygen. MBio 7(4):e00990-16

Walker JRL, Lien BC (1981) Metabolism of fluoroacetate by a soil Pseudomonas sp. and Fusarium solani. Soil Biol Biochem 13:231-235

Wang Y, Deng Z, Qu X (2014) Characterization of a SAM-dependent fluorinase from a latent biosynthetic pathway for fluoroacetate and 4-fluorothreonine formation in Nocardia brasiliensis. F1000Research 3:61 
Wang XS, Liang J, Li L, Lin ZJ, Bag PP, Gao SY, Cao R (2016) An anion metalorganic framework with Lewis basic sites-rich toward charge-exclusive cationic dyes separation and size-selective catalytic reaction. Inorg Chem 55(5):2641-2649

Wang JB, Ilie A, Yuan S, Reetz MT (2017) Investigating substrate scope and enantioselectivity of a defluorinase by a stereochemical probe. J Am Chem Soc 139(32):11241-11247

Wang Y, Davis I, Shin I, Wherritt DJ, Griffith WP, Dornevil K, Liu A (2019) Biocatalytic carbon-hydrogen and carbon-fluorine bond cleavage through hydroxylation promoted by a histidyl-ligated heme enzyme. ACS Catal 9(6):4764-4776

Whittaker JW (2003) Free radical catalysis by galactose oxidase. Chem Rev 103(6):2347-2364

Winkler M, Domarkas J, Schweiger LF, O'Hagan D (2008) Fluorinase-coupled base swaps: synthesis of $\left[{ }^{18} \mathrm{~F}\right]-5^{\prime}$-deoxy-5'-fluorouridines. Angew Chem Int Ed 47(52):10141-10143

Yeo WL, Chew X, Smith DJ, Chan KP, Sun H, Zhao H, Ang EL (2017) Probing the molecular determinants of fluorinase specificity. Chem Commun 53(17):2559-2562

Zechel DL, Reid SP, Nashiru O, Mayer C, Stoll D, Jakeman DL, Withers SG (2001) Enzymatic synthesis of carbon-fluorine bonds. J Am Chem Soc 123(18):4350-4351

Zechel DL, Reid SP, Stoll D, Nashiru O, Warren RAJ, Withers SG (2003) Mechanism, mutagenesis, and chemical rescue of a $\beta$-mannosidase from Cellulomonas fimi. Biochemistry 42(23):7195-7204
Zhang Q, Dall'Angelo S, Fleming IN, Schweiger LF, Zanda M, O'Hagan D (2016) Last-step enzymatic fluorination of cysteine-tethered RGD peptides using modified Barbas linkers. Chemistry-A European Journal 22(31):10998-11004

Zhou Y, Wang J, Gu Z, Wang S, Zhu W, Aceña JL, Liu H (2016) Next generation of fluorine-containing pharmaceuticals, compounds currently in phase II-III clinical trials of major pharmaceutical companies: new structural trends and therapeutic areas. Chem Rev 116(2):422-518

Zhu X, Robinson DA, McEwan AR, O'Hagan D, Naismith JH (2007) Mechanism of enzymatic fluorination in Streptomyces cattleya. J Am Chem Soc 129(47):14597-14604

Zhu XM, HackI S, Thaker MN, Kalan L, Weber C, Urgast DS, Yim G (2015) Biosynthesis of the fluorinated natural product nucleocidin in Streptomyces calvus is dependent on the bldA-specified Leu-tRNAUUA molecule. ChemBioChem 16(17):2498-2506

\section{Publisher's Note}

Springer Nature remains neutral with regard to jurisdictional claims in published maps and institutional affiliations.

\section{Submit your manuscript to a SpringerOpen ${ }^{\odot}$ journal and benefit from:}

- Convenient online submission

- Rigorous peer review

- Open access: articles freely available online

- High visibility within the field

- Retaining the copyright to your article

Submit your next manuscript at $\boldsymbol{\text { springeropen.com }}$ 